\title{
NOMBRES Y PAISAJE
}

\author{
Manuel María Ruiz Urrestarazu
}

Bengoetxea 1. 01194-BERROSTEGIETA (Álava, España). Correo electrónico: orokietae@ yahoo.es

\begin{abstract}
Resumen
Los nombres de lugar (montes, campos y localidades habitadas) reflejan a lo largo del tiempo los distintos componentes que integran el paisaje que nos rodea, haciendo de nosotros intérpretes necesarios en la comprensión de la Naturaleza humanizada, del ambiente en suma. En un lugar como Álava que se sitúa en una conjunción de estaciones edafoclimáticas diversas, a lo que hay que añadir el sustrato lingüístico y los aportes y evolución posteriores, la constatación histórica de los nombres de lugar, de la toponimia, configura un retrato cambiante del paisaje a lo largo del tiempo. En el trabajo que se presenta analizamos los principales sistemas forestales alaveses, arbóreos y arbustivos principalmente y su huella toponímica en esta provincia vasca que, por su ubicación, contacta e intersticia con comarcas en que nacieron o prosperaron los romances españoles centrales. Tal circunstancia hace que la evolución de los nombres aplicados vaya pareja con la del paisaje receptor de aquellos.
\end{abstract}

Palabras clave: Lenguas en contacto, Nombres de lugar, Sistemas forestales, Paisaje, Evolución

\section{VITORIA Y ÁLAVA}

La actual ciudad de Vitoria-Gasteiz era en el siglo XII una aldea denominada Gastehiz, nombre euskérico de significado desconocido para mí, situada en una colina alargada, en forma de almendra, tendida de norte a sur, dominando visualmente la Llanada occidental alavesa, que el monarca reinante, Sancho VI El Sabio de Navarra, amuralló y fundó como Villa en 1181, otorgándole el nombre de Victoria.

Victoria breve, pues en el año 1200 Alfonso VIII de Castilla conquista la mayor parte del territorio vasco que pertenecía a Navarra a poniente de su actual límite occidental, salvo algunas zonas al norte y sur de la Sierra de Toloño o Cantabria, que divide la Montaña y la Rioja alavesas, así como la Sonsierra riojana logroñesa al norte del río Ebro. Pero más breve aún que la deseada Victoria del fundador de la villa fue la de la vigencia de su nombre latino, que derivó a Vitoria desde el inicio a causa de la pronunciación vasca de sus habitantes, pronunciación que repugnaba la dicción "-ct-". Vitoria quedó así de nacimiento apeada de la "c". Hasta en los documentos oficiales castellanos posteriores se da carta de naturaleza a ese nombre vulgarizado, como es el caso del que constata la concesión del título de ciudad a Vitoria en 1431 por parte de Juan II de Castilla, donde se escribe Vitoria, que también aparecerá escrita con la grafía Bitoria en la cédula real de Enrique IV que otorga a la ciudad la calidad de leal, indistinción B-V que también se corresponde con la del vasco ante ambas consonantes.

De ahí que el nombre oficial de VitoriaGasteiz no es en puridad la unión de los nombres castellano y vasco de la ciudad, como pareció pretenderse en su adopción en 1979 por el Ayuntamiento de Vitoria, sino que resulta ser la adición de dos apelaciones vascas de diferente significación aplicadas a un mismo lugar. 
Lo anterior viene a cuento de manifestar la importancia histórica de la presencia de la lengua vasca en buena parte de Álava, en los nombres de poblaciones, montes y campos, en la toponimia en suma, sobre todo en el norte, centro y este de la provincia, con presencia asimismo de los romances navarro y castellano por el sureste, sur y suroeste del territorio, como veremos en nuestro recorrido.

Aunque Álava ofrezca su imagen más vista como una tierra de cultivo agrario rodeada o salpicada de montes de silueta gris, los bosques tienen en el territorio una importancia relevante, ofreciendo un paisaje variado a aquel observador que se aleja de los llanos más transitados.

Pasaremos revista primero a los bosques principales en cuanto a extensión y dominancia y luego saltaremos por los bosquetes, grupos o golpes de árboles y arbustos del cortejo de aquellos, a fin de obtener un retrato, aunque sea algo difuso, de Álava y su paisaje forestal.

\section{SISTEMAS MAYORES FORESTALES}

Abordamos aquí la relación de bosques principales de Álava, formados por los pinares y sobre todo por la extensa foresta de cupulíferas, representada por los robledales, hayedos y encinares, que constituyen los sistemas mayores forestales de esta provincia y que han dejado la impronta de su evolución en el paisaje, retratada en el tiempo a través de los nombres de lugar que describen su presencia.

\section{Los pinares}

A grandes rasgos, los pinares naturales en Álava aparecen en su mitad oeste, a occidente del meridiano de Vitoria, por razones principalmente climáticas y de difusión de las especies. Existe la salvedad de la presencia de Pinus halepensis Mill. en la Rioja Alavesa, en su extremo sureste, junto a Navarra, donde destaca el "Pinar de Dueñas" (Monte ${ }^{\circ} 173$ del Catálogo de MUP), en Labraza, que es la última masa natural compacta de pino carrasco Ebro arriba, por su margen izquierda, si bien hay grupos e individuos sueltos más al oeste, cuya naturalidad será probablemente objeto de estudios posteriores.
Pinus sylvestris L. es la especie más abundante en Álava y se tiende de sur a norte desde los 1200 m en la Sierra de Árcena a los 200 m en Artziniega, marcando así un mínimo altitudinal en la Península Ibérica, dándose la paradoja en esos parajes cantábricos de situarse el pino silvestre natural por debajo en ocasiones de los pinares de Pinus radiata D. Don de repoblación posterior.

El pueblo de Pinedo, en Valdegovía, se cita con tal nombre ya desde el año 809. En Valderejo el principal monte boscoso de dicho valle, catalogado con el no 145 de los de UP, se denomina "Polledo" y alberga en su seno, cabe la roca caliza orientada al norte, un hayedo conocido como "El Hayal de Polledo".

El monte de UP $n^{\circ}$ 589, de Antezana de la Ribera, conocido como "La Lastra y Pinas", nos muestra la denominación con que en el suroeste de Álava se conoce a Pinus pinaster Ait., "pina". La "pina", en contraposición al "pino" (pino silvestre), adquiere para el pueblo un carácter más femenino, probablemente por el tamaño de sus piñas. Fenómeno lingüístico que se repetirá en Artziniega con el "fresno" y la "fresna", siendo el primero Fraxinus excelsior L. y la segunda Sorbus aucuparia L., cuyos llamativos frutos rojos le atribuyen condición femenina. En cuanto a la distribución de Pinus pinaster Ait. en Álava, esta especie sigue la pauta de Pinus sylvestris L., desde Sobrón en el Ebro hasta Artziniega, pero con presencia mucho menos frecuente, limitada en buena parte por las condiciones del suelo, al ser la "pina" más exigente con la permeabilidad edáfica y preferir una mayor iluminación ambiental.

La presencia natural de Pinus pinea $\mathrm{L}$. en Álava se limita a La Llana de Antepardo en Fontecha, donde al construir el Polígono Industrial de Lantarón desaparecieron la mayor parte de los pocos pinos que quedaban en el llano, ya muy disminuidos en número por los cultivos anteriores y aunque se preservaron algunos ejemplares de gran copa como ornamento vinieron a morir por los daños irreversibles provocados a su sistema radical a causa de las obras del viario y pabellones. Hoy queda una alineación principal en una terraza sobre la margen izquierda del río Ebro, a $500 \mathrm{~m}$ de altitud y el árbol de mayor tamaño de todos ellos está catalogado como Árbol Singular, debido a tratarse de 
la única manifestación de esta especie citada como pinar natural en la Comunidad Autónoma.

Hemos podido observar hasta ahora que los nombres vulgares para hablar de los pinos en Álava son castellanos. Dada su distribución espacial en las zonas donde la lengua vasca tuvo menor presencia o desapareció hace tiempo, no tenemos constancia de denominación histórica vasca de los pinos en Álava. Con la introducción de la especie Pinus radiata D. Don los caseros vascos dieron en llamar piñu al pino, acepción moderna que ha quedado como "standard" en vasco, aunque en la Navarra oriental, además del nombre roncalés ler, así como en la Sola (región vascofrancesa conocida como la Soule en francés y Zuberoa en vasco) se conocía hasta hace poco al pino como pino, de lo que ha quedado constancia en toponimia vasca de Navarra y País Vascofrancés (así Pinodieta, Pinadia), en derivación directa del latín, que de Fagus dio fago y formas derivadas y de Pinus pino, coincidiendo en este caso la palabra vasca con la castellana.

\section{Los robledales}

Los robledales, en su conjunto pluriespecífico, constituyen el bosque dominante del territorio alavés, al que siguen en extensión los hayedos, los encinares y los pinares.

Las especies Quercus robur L. y $Q$. petraea (Matts.) Liebl. han dejado huella toponímica ambas (si bien predomina la primera en el País Vasco) como (h)aritz y (h)aretx, perteneciendo la primera variante al euskera central, constituyendo hoy la denominación "standard" y la segunda al vasco occidental. En Álava han convivido ambas y el nombre ha oscilado con el tiempo, dándose la curiosidad de que la población de Aretxabaleta, hoy integrada físicamente en Vitoria, se decía al parecer Haritzabaleta en 1025 , según se colige del documento conocido como la Reja de San Millán de la Cogolla, donde figura como Harizavalleta.

Por poner unos ejemplos de nombres de poblaciones, encontramos Aresketa, barrio de Amurrio, Arespalditza, pueblo del Valle de Ayala, Aretxaga, pueblo del Valle de Zuia y barrios de Lezama y Saratxo; como barrio del oeste de Vitoria destaca por su nombre y significado recio el de Ariznabarra, con su raíz en (h)aritz.
El nombre actual de árbol en vasco, zuhaitz o arbola, en su primera forma de zuhaitz parece haberse referido con anterioridad al roble, como variante de haritz y así tenemos los pueblos alaveses de Zuhatza (Ayala), Zuhatzu (Ganboa, Kuartango, San Millán y Vitoria) y el pueblo de Zuhatzola (Barrundia), citados ya algunos de ellos desde 1025.

Otros topónimos referidos a los robles de hoja caduca, aludiendo al parecer a su bellota, son los de Kukuma, en Araia y Kuskumendi, en Amurrio.

Arimotz. Arimotz, roble mocho. La práctica del trasmochado se aplicó desde hace siglos, como método cultural de obtener leña periódica y permitir el pastoreo universal bajo los árboles descabezados. Se aplicó tanto a robles como a hayas, perviviendo más en estas y llevando a muchas personas, sobre todo en los territorios costeros de Bizkaia y Gipuzkoa, a creer que el porte natural del haya era de fuste bajo y ramas en candelabro.

Al trasmochar los robles se convirtieron léxicamente en vasco en arimotz o arimotzak en plural y así pasó tal apelativo a convertirse en topónimo, como es el caso de las Reservas Forestales de Los Arimotxes, en Munain y Los Arimotxis, en Okariz, al este de la Llanada Alavesa. En Astrain, en la Cuenca de Pamplona, se repite el nombre de "arimoches" para robles quejigos trasmochados. En el caso de las reservas forestales alavesas citadas los árboles centenarios trasmochos son básicamente Quercus robur L., si bien abundan formas híbridas de las que es difícil establecer sus orígenes específicos o cruzamientos, máxime tras la evolución secular de la flora y de las condiciones del entorno; son árboles impresionantes por su tamaño, sobre todo diamétrico, que ya hace una década larga llamaron la atención de la asociación inglesa "Ancient Tree Forum", en su búsqueda europea de árboles longevos singulares. Al disminuir la presión ganadera a mediados del siglo XX un cortejo de Acer campestre L. y Fagus sylvatica L. puso en peligro la vivencia de los viejos robles, por lo que la administración forestal alavesa procura el equilibrio forestal del lugar, priorizando la pervivencia de los grandes trasmochos mediante los tratamientos oportunos. 
Una reflexión anecdótica acerca del trasmochado en nuestro entorno es que parece haber persistido más en aquellos lugares que mantuvieron más tiempo la lengua y los modos culturales vascos, influyendo también la mayor densidad de población (casos de Agurain/Salvatierra o Legutio). En el Parque Natural de Gorbeia observamos que la mayor representación de arbolado trasmocho se da en el municipio de Zigoitia, donde el euskera perduró más que en el de Zuia.

Otra curiosidad de la selvicultura histórica es que la especie que más se apreciaba como árbol bravo dentro de las Fagáceas era Quercus petraea (Matts.) Liebl., como podemos ver en bosques de Legutio, en que robles de fruto sentado sin podar destacan en medio de robles pedunculados y hayas trasmochos (así en los montes Motzotegi y Albertia). En otras ocasiones observamos, en el mismo Legutio, que se hizo un trasmochado a más altura, 3-4 m, para Quercus petraea (Matts.) Liebl. que para el haya circundante, cortada a 2-2,5 m (caso del monte Itesasi).

El carácter de bravo se designaba en vasco por la palabra tantai, que en el Valle de Zuia ha dado tentaio, debidamente masculinizado al pasar al "castellano". ¿Vendría tantai del castellano "tente"?

Quercus faginea Lam. y $Q$. pubescens Willd. (este último poco abundante en Álava) según los registros toponímicos se llaman $(h)$ aritz en vasco y roble en romance, si bien conviene entretenerse en matices nominales. Todavía en el Condado de Treviño (Burgos) y zonas aledañas de Álava pervivía hasta hace poco el nombre de "robre" aplicado al grupo de los robles.

El conocido hoy como roble quejigo o quejigo a secas tiene un nombre peculiar en el Valle de Kuartango y es el de "gacico". ¿Es un gaziko vasco o variante de cajigo? Los actuales pueblos de Caicedo Sopeña (Ribera Alta) y Caicedo Yuso (Lantarón; hubo un Caicedo Suso, hoy despoblado, junto al lago de Caicedo o Arreo) aparecen escritos en 1025 como Cassicedo, pronunciado quizá Caxicedo y luego Cajicedo, que dieron al final Caicedo (robledo de quejigo) y ambos se sitúan en sendos cajigales. Cajigo o quejigo significa de suyo roble pequeño; en documentos del siglo XVIII, al hablar de plantaciones de robles para la Marina, se habla de plantar "cajigos de roble", refiriéndose a plantas o plantones de roble de hoja caediza.
Quercus pyrenaica Willd. nos ofrece un perfil lingüístico algo distinto, más específico, si bien en Valdegovía será llamado roble. Su nombre vasco es ametz y así hay dos poblaciones, en los Valles de Zuia y Aspárrena, que se denominan Ametzaga, si bien la última de ellas se inscribe hoy en un quejigal, por lo que la especificidad de ametz podría ofrecer alguna duda y quizá abarcase en algunos casos al quejigo; a este tenor procede citar el peculiar nombre vasco de ezkametz, literalmente un híbrido, que traduciríamos al castellano como "rebollo de roble" y que se aplica a robles quejigos, pubescentes o híbridos y es un nombre recogido en los valles navarros de Anué, Imotz y Odieta.

En Álava oriental la palabra ametz ha sufrido alteraciones por la población rural que había perdido el conocimiento de la lengua vasca y así, cuando la pérdida era reciente se quedaba en "amez", como en el pie de monte de la Sierra de Elgea-Urkilla, pero si dicha pérdida era más antigua la diferencia era mayor, como sucede en la Montaña Alavesa, en concreto en la zona de los robledales de Izki, que hasta mediados del siglo XX se conocía como Selva de Izki, hoy Parque Natural de Izki, donde el nombre original ametz se convirtió en "almez", probablemente al imponer el artículo masculino (en vasco no hay géneros, mientras que en castellano los árboles son masculinos) a "amez", dando "el amez" y luego "el almez". En Izki llaman "roble albar" a Quercus robur L., mientras que "roble almez" es Quercus pyrenaica Willd.

En los alrededores del monte Gorbeia a Quercus pyrenaica Willd. se le conoce como "tocorno" o "roble tocorno", nombre derivado del vasco occidental tokor, por roble tortuoso o de conformación inferior a la del "roble fresnal", nombre aplicado al roble pedunculado en la zona, que en el Valle de Ayala se conocerá también como "roble avío".

Es de destacar la no existencia vulgar en Álava del nombre "melojo" o "marojo", introducido recientemente en Euskadi por los profesores y alumnos de la Universidad del País Vasco. Sí aparece el nombre de "rebollo", pero en la Bizkaia encartada, en Las Encartaciones, existiendo curiosamente un quejigar en Villabuena de Álava, en la Rioja Alavesa, al que llaman "El Regollar". 
Abordando otra faceta de la historia forestal, se presentan los bosques de Quercus pyrenaica Willd. en Álava en zonas de suelo arenoso lavado, que coinciden a la vez históricamente con lugares donde ha habido incendios reiterados de origen pastoril: Gorbeia, Sierra de Elgea y Montes de Izki son a tal efecto testigos de ese proceso atávico; la capacidad de este roble de renovar de raíz su parte aérea ha podido favorecer su prevalencia frente a otras especies de roble que gustan de hábitats menos recorridos por incendios frecuentes. Ese testimonio, por razón de evolución vital y cultural, va convirtiéndose venturosamente en relato histórico pasado.

\section{Los hayedos}

Aunque los robles, en su conjunto, ocupan en Álava más superficie que el haya, los hayedos o hayales se extienden sobre algo más de 30.000 ha, lo que equivale al $10 \%$ de la superficie provincial y al $21 \%$ del bosque arbóreo alavés. Es el árbol de montaña por excelencia de Álava y en los últimos siglos, al menos desde el siglo XVII, ha ido ganando terreno a los robles y a los pinos silvestres en sus áreas de contacto.

Esa progresión ha sido más evidente allí donde hubo más apetencia en aprovechar la madera de roble, como fue el caso del bosque de Altube que, situado en vertiente cantábrica, se incluyó en los territorios destinados a abastecer de madera a la Marina, figurando entre los montes asignados al Corregimiento de Vizcaya en el siglo XVIII.

El haya, aparte de proveedora de madera, lo fue tanto o más de leña, siendo objeto de trasmoche en las mismas zonas que los robles, de acuerdo con una práctica de la que hemos hablado al tratar de estos. Pero además en otros lugares, como es el caso de los montes de Altube, se realizaron extensas cortas por el pie para proveer de carbón vegetal a las ferrerías. Así el bosque de Altube, que en la actualidad sería el hayedo más extenso de Álava y está incluido en el Parque Natural de Gorbeia, es un gran monte bajo en cuanto a tratamiento secular anterior.

La saga toponímica del haya se basa en el área euskaldun del territorio en dos de las tres apelaciones que el haya ha tenido en lengua vasca: bago y pago (hoy forma "standard" esta última), faltando la de fago, que aparece más al este, desde los ríos Urumea y Bidasoa hasta el
Pirineo oscense. Así encontramos en la Montaña Alavesa los nombres de Bagaio y Baio (este último evolución del anterior: Bagaio, Baaio, Baio, al perderse el significado vasco), ambos topónimos en la Sierra de Entzia, Bagaduia y Bagamendi, en la Sierra de Iturrieta-Ibisate, todos ellos sinónimos de hayedo o monte de hayas, Bagatzederra (hayedo hermoso), en Lagrán en el siglo XVIII, convertido luego en "Cabezaerra"; al norte de Álava, entre Legutio y Ubarrundia encontramos Bagoeta (conjunto de hayas), Bagatza (hayedo), que aparecerá en Urkabustaiz y Arespalditza al noroeste de Álava. La forma pago será dominante al norte, centro y oeste de Álava, con Pagaduia, Pagatza y Pagoeta (hayedos), desde la Sierra de Elgea hasta Okendo, pasando por Gometxa (al suroeste de Vitoria).

Mención aparte merece, por su originalidad, el nombre antiguo de la población de Payueta, junto a Peñacerrada, citada como Pagoeta por Labayru (1895) y que hoy es su nombre oficial, que en 1257 Jerónimo Aznar, obispo de Calahorra, en la descripción geográfica que realiza, cita como Fayoeta. Si la cita es correcta, tendríamos ahí el nombre de fayo aplicado al haya. Un monte próximo a Payueta, algo más al sur, el $n^{\circ} 185$ de los de UP, se inscribe como "Argomal", pronunciado también "Argumal" por vecinos de Peñacerrada, pueblo al que pertenece el monte, cuando la población campesina alavesa mantiene por casi toda Álava el nombre vasco de otaka para referirse a Ulex spp. Alcanza quizá ahí la zona o banda de contacto de los romances periféricos y el castellano propiamente dicho, lengua esta última que se definirá con más claridad en las marcas occidentales de Álava que lindan con las Merindades burgalesas.

Finalmente, pasando al romance, en Valdegovía los hayedos dieron preferentemente en hayales en el habla castellana de la comarca, si bien aparece aquí y allá en el valle algún nombre suelto en euskera, como sucede con el del pueblo de Basabe (bajo el bosque), situado junto a Pinedo, pueblos citados desde 1175 y 809 respectivamente. Existen también mixturas lingüísticas en la zona, como es el caso del Monte Valdapa (valle de la cuesta), $\mathrm{n}^{\circ} 17$ de los del Catálogo de UP, perteneciente a Astúlez. Pasando ahora del haya al pino, además de pinedo para bosque de pinos se ha empleado también 
la palabra pinal, palabra que pasó al castellano hablado por los caseros vascos de la primera mitad del siglo XX para referirse a los pinares plantados de Pinus radiata $\mathrm{D}$. Don en la vertiente cantábrica y es que muchos de ellos aprendieron castellano en pueblos de Álava, además de la posible influencia de maestros procedentes de zonas en que tal abundancial se empleaba.

Hayas, robles y pinos. Yendo al norte de la provincia, hacia la divisoria de aguas vertientes a los mares Cantábrico y Mediterráneo, cuencas de los ríos Altube-Nervión y Bayas-Ebro y en el macizo montañoso de Gorbeia, es curioso observar en la cabecera del monte cantábrico Altube, $\mathrm{n}^{\circ} 59$ de los de UP, de la pertenencia de Baranbio, la presencia de pinos silvestres seculares coronando, a $900 \mathrm{~m}$ de altitud, el bosque de robles (de fruto sentado y pedunculados) y hayas que ocupa las laderas inferiores. Ya en vertiente mediterránea, a poca distancia del lugar anterior y dentro del MUP ${ }^{\circ}$ 734, Altube y Gorbeia, encontramos el relicto "Pinar de Indusi", testigo remanente aunque caduco de un cambio climático acaecido entre los siglos XVI y XX, en el sentido de una mayor neblinosidad y templanza, que ha favorecido sobre todo al haya y ha ido en detrimento tanto del roble de fruto sentado como del pino silvestre.

\section{Los encinares}

Quercus ilex L., tanto en su subespecie ilex como ballota, tiene en Álava una triple denominación: arte en lengua vasca y encina o carrasca, indistintamente sin asignación subespecífica, en castellano actual.

Del primer nombre, arte, derivan los pueblos de Artatza, en Foronda y Lacozmonte, que en el año 1025 se dirían Artatzaga (transcrito como Artazaha en el documento de la Reja de San Millán de la Cogolla). Se encuentran respectivamente al pie de las Sierras de BadaiaArrato y Arkamo, en el centro-oeste de Álava, donde se sitúan los encinares más extensos de la provincia, en esas sierras de suelo somero y roca caliza aflorante.

Tienen también denominación vasca, los montes de UP n ${ }^{\circ} 370$, Artazu (encinar o encinoso), de Apodaka (Zigoitia), al noroeste de Vitoria, no 387, Artadoia (encinar), de Korres (Maeztu), en la cuenca del río Ega y $n^{\circ} 437$,
Artearana (valle de la encina), de Elburgo, en la Llanada Alavesa. Vitoria ha subsumido en su zona industrial un trampal llamado Artapadura (tremedal de la encina).

En cuanto a los nombres de carrasca y encina, 7 montes del Catálogo de UP aparecen con el nombre de encina, de los que 2 como "El Encinar", 4 como "Encinal" o "El Encinal" y 1 como "Sierra de la Encina", que se sitúa a partir del Santuario de $\mathrm{N}^{\mathrm{a}} \mathrm{Sr}^{\mathrm{a}}$ de la Encina, en Artziniega, santuario que data de 1514 y en cuya fachada norte hay un ejemplar viejo de encina, de gran tamaño aún, catalogado como Árbol Singular. Como curiosidad indicamos que el Monte de UP no 453, denominado "Encinal", pertenece al pueblo de Artatza, en Foronda, siendo encinal sinónimo romance del artatza vasco. 6 montes de UP comprenden el nombre de carrasca, agrupado en 5 ocasiones en el de "Carrascal" o "El Carrascal" y en 1 caso en el de "Carrascales". Por encontrar alguna pauta, el nombre de carrasca se aplica más en el sureste de Álava, en la cuenca del río Ega y el de encina en el oeste de Álava, con la excepción de Añes (Ayala) y Domaikia (Zuia) que dan carrasca, por lo que la pauta expuesta no es concluyente.

\section{SISTEMAS MENORES FORESTALES}

Inmersas en los bosques dominantes y adquiriendo singularidad con frecuencia, las especies menores en cuanto a representación presentan un interés toponímico y por ende paisajístico, de relieve. En épocas en que los usos de los montes estaban más diversificados, los bosques presentaban menor densidad arbórea y los árboles no eran raros en un campo parcelado con parsimonia, las especies secundarias eran testigos de un monte y un campo más animados por los recorridos del hombre de campo, que lo era de campo y monte, donde encontraba el complemento de suministro que el campo por sí sólo no satisfacía, en el caso de la población campesina de otro tiempo.

Los nombres de ese bosque variado, de esas pinceladas de vegetación difundida por montes y campos nos ocuparán en el siguiente análisis, que empezará por los árboles que llamaremos de segunda fila y terminará por los matorrales más extensos. 


\section{EI tejo}

El tejo o (h)agin, nombre vasco con el que se le conoce en buena parte de Álava a Taxus baccata L., va desde las estribaciones de la Sierra Salvada o Gorobel, al noroeste, donde ya en 1114 se cita el pueblo de Aginaga ("Aguinaga" en la transcripción), que vendrá a decirse "Aguíñiga" a partir del siglo XIX, hasta la Sierra de Cantabria o Toloño en el sur, en que los "aguines" sobremontan el hayedo cerrado colgándose de los farallones verticales de la sierra, por la cara norte de la misma, pasando por los pinares, robledales y hayedos alaveses, apareciendo el testimonio de su nombre a través de los montes, como es el caso de Aginamendi (monte del tejo o de los tejos), sobre el "Pinar de Indusi” que citábamos anteriormente.

\section{El nogal}

Juglans regia L. Árbol cercano a la habitación humana, ocupó lugar preferente junto al caserío aislado o agrupado, alternando en ocasiones con la encina por su aportación de fruto y ha dejado poca impronta en los nombres montaraces. Conocido como intxaur en vasco, tanto el fruto como el árbol en buena parte de la toponimia en euskera, encontramos un monte en Víllodas (Iruña), el $\mathrm{n}^{\circ} 502$ del Catálogo, denominado Intxaurte (nocedal) y otro, el $\mathrm{n}^{\circ} 201 \mathrm{en}$ Payueta (Peñacerrada), llamado "Los Nogales y La Manzanera", en esa zona ya citada en que el romance se entrevera con el vascuence.

\section{El pobo y el chopo.}

En 1562, en su Dictionarium Linguae Cantabricae, Nicholaus Landuchius, viajero italiano que recogió un extenso elenco de palabras vascas y su significado durante su estancia en Vitoria, dice que errexal equivale a árbol y que errexal zuri es álamo blanco y errexal baltz (balza escribe) álamo negro. Puede que así se le informara a Landuchio y que así fuera en el siglo XVI en Vitoria. Al tratar de los fresnos veremos que errexal parece ser una transposición de lexar, fresno, con adición de "e-" epentética ante "r-" inicial. De todos modos, la presencia de los álamos blanco y negro en Vitoria no parece haber sido cuantiosa a tenor de la escasa huella toponímica que encontramos en su entorno próximo y en toda Álava.
Populus alba L. y P. nigra L. se presentan preferentemente en las orillas del río Ebro y de los cursos medios y bajos de sus afluentes, habiendo dejado poca huella toponímica en Álava hasta mediados del siglo XIX, tanto en lengua vasca (en que las denominaciones de ambas especies son imprecisas y en muchos casos traducidas) como castellana. El nombre de chopera aparecerá luego por doquier en el siglo $\mathrm{XX}$, a una con la generalización de las pequeñas plantaciones de chopos (dada la estrechez de las riberas alavesas).

Procede destacar, no obstante, el nombre de la población de Pobes (Ribera Alta), en la margen derecha del río Bayas, citada así desde 1091 o los nombres de El Pobar, junto al río Omecillo, en Bergüenda (Lantarón) y La Póbeda, en la margen izquierda del Ebro, en Lapuebla de Labarca (Rioja Alavesa). En cuanto a topónimos del chopo, en 1724 se registra un labrantío en Villafranca (Vitoria) llamado Choposoloa (la pieza o campo del chopo), nombre compuesto en mezcla de idiomas, hecho que incide en la relativa indefinición de los nombres vascos referidos a los chopos o álamos de ribera.

\section{El chopo temblón}

Populus tremula L. El chopo de monte resulta un árbol llamativo por el temblor de sus hojas y su corteza clara y en lengua vasca ese temblor se ha convertido en su nombre, bien de manera literal como ikara (temblor), registrándose en 1732 en Musitu (Laminoria) el término Ikaraduia (temblar), como más frecuentemente a través de onomatopeyas, así las de lertzun, zuzun y susun en toponimia alavesa, donde encontramos Lertzundi en Legutio, Zuzundui en Okoizta (Zigoitia), Susuneta en Letona (Zigoitia) o Susuntza en Anuntzeta/Anúcita (Ribera Alta). Ya desde 1699 encontramos "El Temblar" dentro del robledal de Izki, en la zona perteneciente a Korres (Maeztu) y también permanece vivo el antiguo término de "Tremoledo" en una de las mojoneras del sur de la Sierra Salvada, a caballo de Burgos y Álava.

\section{Los salces}

El género Salix prestó nombre al romance salce, luego sauce, citándose el actual pueblo de Salcedo como "Salceto" en el año 873. Y también 
lo hizo al vasco sahats, sagats, sarats, que vemos en los Saratsaga, Saratxaga, Sagatsageta (nombre del pueblo treviñés de Sáseta en la Reja de San Millán de 1025, donde se transcribe como Sagassaheta), Sarasketa, todos ellos con el significado de sitio de salces o sauces o salcedo, sauceda.

Desde el Valle de Ayala hasta Kanpezu/Campezo aparecen topónimos derivados de mihimen (mimbre), del latín viminalis: Mimentza, Mimenduia, Mimitzaeta, referidos a mimbrerales.

Otros nombres vascos de los sauces que se recogen en Álava son los de zuma y su variante zumaka, como es el caso del barrio vitoriano de la Zumakera, donde al zumaka vasco se añade la desinencia romance "-era". No era extraño en la zona central de Álava referirse a los sauces como "las zumas", así en femenino por la terminación en "-a" de la palabra vasca zuma.

\section{Los abedules}

Betula alba L. y B. pendula Rothm. Ambas especies contactan en Álava, apareciendo la primera en el Cantábrico y la segunda en la Montaña. El nombre vasco del abedul, urki, ofrece una serie de topónimos, de los que destacamos el conocido Urkijo, con su variante de Urkillo, referidos probablemente a abedular o conjunto de abedules. Otro sinónimo de abedular es Urkitza, que aparece en la Sierra de ElgeaUrkilla (de posible idéntico significado), Valle de Arana y Mioma (Valdegovía), palabra que en el alto Arlanzón burgalés nos dejaría "Urquiza" y "Uzquiza". En el Valle de Zigoitia se usaba en el habla popular para referirse al abedul una variante de urki que es epurki, de la que no conozco registro toponímico y que recuerda a la forma burki que se emplea en la Sola (Zuberoa/Soule, País Vascofrancés), donde sí hay topónimos en burki, así Burkidoi (abedular).

\section{El aliso}

Su nombre vasco de $(h)$ altz aparece en toponimia de la mitad norte de Álava, si bien no con la profusión que en las provincias vascas costeras, donde la humedad de suelo promueve una abundancia nominal pareja a la de su presencia física. Con el significado de aliseda, encontramos por ejemplo un Altsua o Altzua, en Ullibarri Ganboa, que es una variante apocopada del nombre de la población navarra de Altsasu/Alsasua, llamada también Altsu en el vasco del entorno burundés.

Quiero resaltar, a causa de la huella histórica de su denominación romance, el nombre de la villa de Bernedo, de fundación navarra. Citada como Bernedo en 1257 y como Verrnedo en 1292, encierra en su denominación el sustantivo "verno", sinónimo romance de "aliso", que con esa misma forma de "verno" sigue vivo en gascón, como "vern" en catalán y "verne", como segundo nombre de "aune", antiguo "aulne", en francés. Todavía hoy en el entorno de los montes de Izki se mantiene el nombre hipocorístico "verniazo" para referirse al aliso. En la cuenca baja del río Zadorra, en su margen izquierda a la altura de Manzanos (Ribera Baja), hay un término conocido como "Vernal".

\section{El avellano}

En vasco $(h) u r$ se refiere al fruto, a la avellana, pero en toponimia también frecuentemente a la planta de avellano, que en vasco "standard" se conoce como (h)urritz y como (h)urretx o (h)urrutx en vasco occidental, cuyas formas predominan en Álava al referirse al avellano. El nombre de la avellana, ( $h$ )ur es la base de los nombres de los frutos de las cupulíferas en vasco, así $e z k-(h) u r$ (avellana de roble) es bellota, intxa-(h)ur (avellana de nogal) es nuez y nogal, paga-(h)ur (avellana de haya) es hayuco, hove o grana.

En 1138 se cita la desaparecida población de Urretxa (escrito Urrecha), al norte de Vitoria. El Monte de UP $\mathrm{n}^{\circ} 720$, situado en los Montes de Vitoria, al sur de la ciudad se llama "La Nevera y El Avellanal".

\section{El castaño}

Plantados aquí y allá, los castañares alaveses fueron islas en los bosques dominantes o entre cultivos (Sobrón, Quejo, Lagrán, San Román de Campezo, Etxagoien de Zigoitia). El Monte de $\mathrm{UP}^{\circ}$ 705, en los Montes de Vitoria, se denomina Kastañarri (peña del castaño o de los castaños), con la forma vasca occidental kastaina, variante de gaztaina.

\section{Los olmos}

El olmo del llano, Ulmus minor Mill. y el olmo de montaña, Ulmus glabra Huds., tintaron salpica- 
damente con su verde intenso campos y montes de Álava, sin adquirir la predominancia de otros lugares menos neblinosos. Aun así encontramos topónimos vascos como Zugartegi, en Larrea-Hermua, con la forma zugar, que vemos en el conocido Zugarramurdi navarro, cuna de sedicente brujería, junto a la más común de zumar, como en Zumarburu, despoblado junto a Agurain/Salvatierra o Zumarrandi, monte de Zalduondo.

El olmo y su variante lingüística olma tomarán carta de naturaleza romance en los cursos medios y bajos de los afluentes del Ebro, junto a una mayor abundancia física (Condado de Treviño, Ribera Baja, Lantarón, Valdegovía y Rioja alavesa).

\section{Los serbales}

Sorbus aria (L.) Crantz, agustai/mostajo o serbal blanco y S. torminalis (L.) Crantz, azpil o maspil/mostajo, son las especies más abundantes en Álava, la primera como acompañante de los hayedos y la segunda de los robledales, siendo esta especie una de las que primero brota en primavera, por lo que permite un inventario visual-paisajístico de su ubicación en los montes. En cuanto a Sorbus aria (L.) Crantz, ha sido una particularidad de la Montaña Alavesa (Valle de Arana-Laminoria) el mantenimiento del nombre vasco agustai para designar al serbal blanco, mientras que en resto del País Vasco se le conoce como ostazuria (hojablanca); el Monte de UP $\mathrm{n}^{\circ} 87$, situado en la Sierra Salvada, en zona de hayedo, se denomina "Mostajo". En lo que se refiere a Sorbus torminalis (L.) Crantz, azpil, nombre central vasco, se le aplica en la Llanada y Montaña Alavesas y maspil, nombre occidental, en los valles del norte de Álava.

En lo que respecta a Sorbus aucuparia L., su nombre vasco es otsalizar (fresno de lobo, con el significado de fresno silvestre), no habiendo encontrado registro en Álava; sí, como ya indicamos al tratar de la "pina", la referencia a este serbal de cazadores como "fresna" en Artziniega, seguramente por sus vistosos frutos rojos frente a las adustas sámaras del fresno.

Sorbus domestica L. dejó referencias romances en sus zonas de habitación, como "Pomar" en Yécora (Rioja), en 1652, "Pomareda" en Eskota (Lacozmonte), en 1693 y "El Pomal" en Antoñana (Campezo), en 1723; los nombres de "zurba" y "zurbal" referidos a esta última especie son conocidos en los lugares donde se cultivaba o se hallaba asilvestrado, preferentemente en el suroeste de Álava. El nombre vasco de gurbe aplicado a esta especie se halla fonéticamente próximo a los últimos mencionados y encontramos topónimos registrados en el siglo XVIII como Gurba en la Montaña Alavesa (1765 en Maeztu y 1786 en Markiniz), que quizá tuviesen relación con el pomo, aunque es dudoso al ir sin desinencia ni artículo aparente.

\section{El peral}

Pyrus communis L., madari/peral silvestre, en su nombre vasco y como Madaria (con el artículo determinado al final de la palabra), da nombre a un pueblo de Álava cabe la Sierra Salvada, en el Valle de Ayala. El mismo nombre, pronunciado Madaría, lo encontramos en la Navarra atlántica, referido a un barrio de Zugarramurdi. Madariaga abunda en Bizkaia y Gipuzkoa. Para peral silvestre y en vasco occidental se emplea también el nombre de makatz. Dada la ubicación preferente del peral silvestre en estaciones húmedas y de suelo suelto, no ha dejado apenas huella toponímica romance en Álava.

\section{El manzano}

Sagar en euskera es tanto manzana como manzano a efectos toponímicos; con determinadas sufijaciones, el lexema sagast- puede referirse a manzano o sauce, cuestión que se dilucida a través del contexto o del lugar. Tanto en lengua vasca como castellana, encontramos en Álava topónimos referidos a Malus sylvestris Mill. En lengua vasca, los montes de UP $\mathrm{n}^{\circ} 354$, Otsasagastuia (manzanal de lobo, silvestre), de Ozaeta, no 474 y no 475, ambos Sagastuia (manzanal), de Garaio y Orenin y $\mathrm{n}^{\circ} 492$, Otsasagastuia, de Elgea, todos ellos en el municipio de Barrundia. En lengua castellana, ya desde el año 1025 se cita el pueblo de Manzanos (Ribera Baja); también vemos los montes de UP $\mathrm{n}^{\circ}$ 124, "Manzanal y Paúles", de Tobillas (Valdegovía) y no 201, que, como ya vimos al tratar del nogal, se denomina "Los Nogales y La Manzanera" y pertenece a Payueta (Peñacerrada).

Nombres exclusivos para el manzano silvestre son los de sagarmin/maguillo. El primero ha dejado toponimia abundante en las comarcas de 
Estribaciones de Gorbeia, Llanada y Montaña Alavesas y el segundo nombre es frecuente hoy en la Montaña Alavesa.

\section{El cerezo}

La gran rosácea Prunus avium L. aparece sobre todo en montes del norte de Álava, de la divisoria de aguas Cantábrico-Mediterráneo o cercanos a la misma, de la Llanada oriental y de la cabecera del Ega, ofreciendo topónimos basados en la forma occidental vasca kerezi, frente a la "standard" gerezi, siendo frecuentes los nombres de lugar a partir de kerexa (de kerezia), como por ejemplo Kerexeta (cereceda), que luego dio Kerejeta, escrito muchas veces con la grafía castellana Querejeta.

También encontramos cerezos en los montes del suroeste de Álava, ya con su nombre castellano, dando topónimos como "Cereceda", en Bachicabo (Valdegovía) y Comunión (Lantarón).

\section{Los arces}

En Álava conviven los dos nombres vascos que están en la raíz de los que en la actualidad se aplican a las distintas especies peninsulares del género Acer. Tales nombres son ihar o igar y azkar. Ihar, pronunciado como yar, se emplea en el Valle de Arana para designar a Acer opalus Mill., arce de montaña relativamente abundante en los montes de la cabecera de la cuenca alta del río Ega, donde en otoño adquiere coloridos rosados de gran belleza. Azkar, más común en su uso, se aplica en el occidente del País Vasco, registrándose también en toponimia de otras zonas del mismo, para referirse a Acer campestre L.

En la actualidad y en el euskera habitual hoy ihar o igar ha caído en desuso y a nivel vulgar sólo se conoce en los dialectos centrales su derivado astigar, que se compone de asto-igar (arce de burro, esto es arce silvestre) y se emplea para designar al arce campestre; no así en toponimia, donde encontramos numerosos Ihartza o Yartza, Igartza y otros nombres de lugar que mantienen ihar o igar en su composición.

Azkar por su parte y al perderse el uso del euskera en buena parte de Álava dio las formas "azcarro", "ascarro" y "ascarrio", en progresión de lejanía del nombre de azkar, que a su vez podría quizá proceder del Acer latino pronunciado a la manera del tiempo de Cicerón. Dos loca- lidades se llaman Azkartza, una en Álava, cerca de Vitoria, citada como Azkartzaga (Ascarzaha) en 1025 y otra en el Condado de Treviño (Burgos), cuyo nombre oficial es Ascarza, condado donde en su parte oriental y central es frecuente encontrar topónimos de origen vasco.

Otro pueblo, el de Alcedo, en Lantarón, se cita con ese nombre ya en el año 975.

\section{Los tilos}

Siendo escasa en el territorio la presencia de Tilia spp., sin embargo los tilos han dejado cierto testimonio en toponimia menor, en las dos variantes del nombre vasco del tilo, ezki (central-oriental) y ezku (occidental), así Ezkizar, en Larrea (Barrundia), Ezkudi (Lezama) o Ezkutza (Okendo).

\section{Los fresnos}

Aunque la especie más frecuente en Álava es Fraxinus excelsior L., también aparece $F$. angustifolia Vahl en los valles medios y bajos que discurren hacia el río Ebro. En el caso de los fresnos aparecen así mismo en Álava las dos formas vascas lizar (central) y lexar (occidental, derivada de leizar y que de lexar dará también posteriormente lejar). En el pueblo de Larrea (Barrundia) existe un topónimo actual, Lizargibel (tras el fresno), que en siglo XVI aparece como Lexargibel. En el Valle de Ayala se cita en el año 864 el pueblo de Lixarzo, hoy dicho Lejarzo (fresnedo).

Pero además de los dos nombres vascos anteriores, aparecen hasta mediados del siglo XVIII en la parte central de Álava, esencialmente en la Llanada más próxima a Vitoria, topónimos basados en el nombre de errexal, citado ya por Landuchio en el siglo XVI durante su estancia en Vitoria, como hemos visto al tratar de los chopos y que, además del carácter general de árbol que le da Landuchio en su Diccionario, parece ser una transposición fonética de los leizar y lexar anteriores, si le quitamos a errexal la "e-" inicial que el vasco tiende a anteponer a la mayor parte de las palabras que empiezan por "r-“, lo que se ve más claro en topónimos que fueron transcritos sin dicha "e-" inicial, cual es el caso de Rexalza, labrantío de Miñano Mayor (Vitoria) en 1704, que podemos trasponer por Lexarza (hoy se diría Lexartza), es decir fresnedo, con lo que estaríamos ante un nombre más 
del fresno en vasco, nombre ya en desuso. Que el nombre concreto del fresno se generalizara al del árbol en el vasco hablado en Vitoria y alrededores tendría la lógica de su abundancia en la Llanada más fértil.

También la lengua romance da testimonio en Álava de la presencia fraxínica y lo digo así por la curiosidad lingüística que representa el nombre antiguo del pueblo de Fresneda, en Valdegovía, que en 1025 se cita en el documento de la Reja de San Millán de la Cogolla como "Frasceneta" y que si se llegó a pronunciar "Fraxeneta" nos acercaría en su dicción al "Freixenet" catalán y al "fraxino" del Alto Aragón, donde se mantiene tal nombre en su cercanía al nombre latino.

\section{Los enebros}

Juniperus communis L. es el enebro más corriente en Álava. J. oxycedrus L. y J. phoenicea $\mathrm{L}$. aparecen en quejigares y encinares de solanas depauperadas cubriendo bolsadas de tierra. Los enebros en la Álava meridional mantienen la denominación romance de "ginebro" o "jiniebro", con " $\mathrm{g} / \mathrm{j}$ " oscilante en la grafía, dando "ginebrales" o "jiniebrales". En Valdegovía a los enebros pinchudos llaman "grojos".

En cuanto a los nombres vascos de Juniperus communis L., en las inmediaciones del Santuario guipuzcoano de Arantzazu le llamaban juniperu, que valle abajo pasaría a ipuru, no apareciendo este nombre claramente en Álava. En Navarra, desde Roncesvalles (Orreaga en vasco) hasta la Cuenca de Pamplona y Valdizarbe se empleaba el nombre vasco de orre para denominar a este enebro; en Álava, encontramos los topónimos montaraces Orre, en Azua (Ganboa, hoy Elburgo) y Orra, en Arroiabe-Mendibil (Arrazua-Ubarrundia) y otros con derivados de orre en el norte, centro y este de Álava, que podrían referirse al enebro. En el Alto Deba guipuzcoano llaman a Juniperus communis L. Araba otea (argoma de Álava), por su abundancia en esta provincia limítrofe de su valle, donde es más parva su representación.

\section{Los brezos}

Berozos y biércoles son los nombres romances empleados en Álava para las especies de Erica y Calluna, estando el de biércol limitado a la Montaña Alavesa. El Monte de UP n ${ }^{\circ}$ 567, denominado "El Berozal", perteneciente a
Nanclares de Oca y Ollávarre, es monte de Erica vagans $\mathrm{L}$. El brezo arbóreo, E. arborea L., se conoce en la Sierra de Árcena (Valdegovía) como "berozo morisco".

En cuanto a los nombres vascos de los brezos y brecina, el general en Álava es el de ilar(ra) en su mitad oriental y el de iñar(ra) en la occidental. Los pueblos de Ilarratza e Ilarduia (significando ambos brezal), en la Llanada Alavesa, se citan ya en 1025 en el documento de la Reja de San Millán (como Hillarrazaha e Hillardui respectivamente). El monte de UP n ${ }^{\circ}$ 624, también de Erica vagans y perteneciente a Ezkerekotxa y otros, se llama Ilarra. Erica arborea L. se conoce en la Sierra de Elgea-Urkilla y Valle del Deba (Gipuzkoa) como astilarra (de asto-ilarra, brezo de burro o silvestre), derivado también a estilarra en el pie de monte alavés de la sierra mencionada; existe una plantación consorciada en el término "El Estilarral" de esa sierra. En Campezo llaman "guiris" a los brezos de Erica arborea L. y Erica scoparia L.; es posible que se trate de una palabra vasca, giri, en desuso hoy, ya que un monte de San Vicente de Arana, aguas arriba de Campezo, se cita como Giriduia (escrito "Guiriduya") en 1787.

\section{El borto}

Arbutus unedo L. ocupa en Álava zonas relativamente templadas, principalmente al oeste y sureste, allí sobre encinares y pinares termófilos de "pinas" y aquí sobre carrascales de la cuenca del Ega.

En el oeste de la provincia se le conoce como "borto" y existe un monte de UP, el $n^{\circ}$ 148, perteneciente a Lahoz (Valderejo), que se llama "Los Valles y El Bortal". En Lezama, vertiente cantábrica, se sitúa el barrio de Gurbista, topónimo que parece relacionado con gurbitz, nombre vasco del "borto".

Yendo a la cuenca del Ega, en Campezo se le conoce como "burrubiote" o "gurrubiote", apelativo que recuerda a otro de los nombres vascos de este arbolillo, el de gurgu, como le llaman en Urdaibai (ría de Gernika), citándose en 1849 el término de "Burrubioste" para un arbustal de la localidad campezana de Antoñana.

\section{Los espinos}

Crataegus monogyna Jacq. y C. laevigata (Poiret) DC. (esta en la Montaña Alavesa) son 
los espinos blancos que aparecen por doquier en los montes alaveses y que formaron espinares más continuos en los últimos siglos pasados. Prunus spinosa L. será arbusto más campestre, ruderal o de ribera, no tan montaraz como Crataegus en Álava.

Los espinos del género Crataegus son conocidos en vasco como elorri zuri o arantza y los de Prunus spinosa como elorri beltz, aran u okaran (en vasco occidental); en castellano como "espino blanco o majuelo" los primeros y como "endrino", "espino negro" o "arán" (normalmente en plural "aranes") el segundo.

Las poblaciones de Elorriaga (junto a Vitoria), Elortza (Maeztu) y Elosu (Legutio), cuyos nombres se refieren a los espinos, se citan desde 1025 (entonces como Elhorriaga, Elorzahea y Elhossu respectivamente). El despoblado de Okarantza, que se situaba en Zigoitia, significaba endrinal.

Los montes de UP $\mathrm{n}^{\circ}$ 276, "Larrea y Espinal", de Arluzea, Urarte y Markiniz, 427, Gibijo (antiguo Gibillo), comunidad en Kuartango-Urkabustaiz, 491, Elorduizabala (el espinar extenso), de Elgea y otros (Barrundia), 622, Gabilamendi, de Okariz (San Millán) y el monte sin catalogar Kapildui, espinares antiguos de Crataegus todos ellos, fueron colonizados por los robles y sobre todo por el haya en los dos últimos siglos, salvo allá donde los incendios y/o el pastoreo han frenado su expansión; los espinos habían convivido con el ganado merced a sus espinas vulnerantes.

Los textos forestales del siglo XVIII consideraban a los espinos como auxiliares de las plantaciones y recomendaban espinar los plantones de repoblación. Todavía en la primera mitad del siglo XX había guardas que consideraban paso obligado para la regeneración y prosperidad del hayedo la abundancia previa de los espinos blancos. De espino blanco se hacían las crucecitas que se colocaban a las puertas de los caseríos para protegerlos de las adversidades atmosféricas u otras, asociando la cruz con los espinos (por la corona de espinas).

Otros montes de UP hacen referencia a Prunus spinosa L.: los números 472, Okaramendi, de Marieta y otros (Barrundia), 692 y 693, ambos Aranduia, de Villafranca y Aberásturi (Vitoria) respectivamente.

\section{Los otacales}

Me permito la licencia de emplear el nombre híbrido de "otacal", del vasco otaka y el abundancial castellano "-al", porque es así como los argomales son conocidos por el campesino alavés.

En vasco Ulex spp. es ote, ota u otaka y así tres pueblos alaveses llevan su nombre: los de Otatza, en Barrundia y Foronda y el de Otazu, en Vitoria, citándose los dos últimos desde 1025.

Argoma o árgoma es nombre conocido en las capitales y algunas otras localidades vascas, así Peñacerrada, donde tenemos el Monte $\mathrm{n}^{\circ} 185$ de los del Catálogo de UP que se denomina "Argomal", también dicho "Argumal", pero la denominación habitual para la argoma que perdura para el campesino alavés es la vasca de otaka. Tuve ocasión de oír, hará cerca de cuarenta años, en el pueblo de Azazeta y a uno de sus vecinos comentar que un veraneante de San Sebastián que hablaba vasco llamaba a esa planta pinchuda "argoma", mientras que el nombre "castellano" que él empleaba (no conocía el vasco) era el de otaka. En pleno monte de Barrón, en Lacozmonte, en zona castellanizada desde hace siglos, para describir a Genista hispanica L. explicaba un vecino de la localidad que era como una "otaquilla".

En la actualidad y aquende los Pirineos, buena parte de los montes vascos que sustentaban matorral de Ulex spp. han sido repoblados.

\section{El acebo}

Ilex aquifolium $\mathrm{L}$. abunda en suelos sueltos de hayedos, pinares de silvestre y robledales de hoja lobulada (caediza y marcescente).

Su nombre vasco es gorosti, citándose desde el año 1067 la población de Gorostitza, cabe el monte Gorbeia, en el municipio de Zigoitia. Existe también, cerca de Navarra, el Monte de UP n 310 con el mismo nombre de Gorostitza (acebal), perteneciente a Ibarguren (Aspárrena).

El nombre castellano de acebo también ha dejado testimonio toponímico en el oeste de Álava: así la población de Acebedo, en Valdegovía, documentada como "Acevedo" en 1175. Dos montes de UP se refieren a sendos acebales: el $\mathrm{n}^{\circ}$ 10, "Urtale y El Acebal", de Artziniega, al noroeste de Álava y el no 141, "El Acebal", en el suroeste, perteneciente al pueblo 
de Ribera, en Valderejo, monte limítrofe ya con la provincia de Burgos.

\section{El boj}

Buxus sempervirens L. aparece principalmente en la mitad sur de Álava en suelos calizos de roca aflorante y algunos tratadistas atribuyen su frecuencia en nuestro entorno, además de al suelo, a la presencia de vientos dominantes en el sentido de la circulación atmosférica a través del canal eólico del Valle del Ebro.

El Monte de UP n ${ }^{\circ}$ 568, denominado "El Bojal", perteneciente a Nanclares de Oca y Ollávarre, se sitúa al inmediato oeste de la garganta por la que el río Zadorra sale de la Llanada Alavesa para pasar a La Puebla de Arganzón (Condado de Treviño, Burgos). Al este de dicha garganta está el Monte de UP n ${ }^{\circ} 567$, llamado "El Berozal", de la misma pertenencia y ya mencionado al tratar de los brezos. Brezos y bojes, bajo quejigos, encinas y pinos silvestres dicen hasta luego al Zadorra para su transcurso treviñés, antes de volver a Álava a fin de rendir finalmente tributo al Ebro entre Miranda (Burgos) y Zambrana (Álava).

El elenco de nombres dejados por el boj en Álava es curioso por su mezcolanza, propia de los lugares donde aparece, ecotonos físicos y lingüístico-culturales. Así, además del boj académico visto en "El Bojal" de Nanclares de Oca, encontramos al sureste de Álava el topónimo "Bujal" en Villaverde, municipio de Lagrán, al norte de la Sierra de Cantabria o Toloño y en el mismo Lagrán el nombre de lugar Bujumendia (el monte del o de los bojes), el arroyo "Bujo" en Bernedo y el pueblo de Bujanda ("Buxanda" en 1742) en el municipio de Campezo, nombre ambiguo en cuanto a su asignación lingüística a una de las lenguas de Álava. Ya al oeste de la provincia, vemos el barranco de "El Bujarral", entre Hereña y San Miguel (Ribera Alta).

En cuanto al nombre genuinamente vasco del boj, además de las anteriores aproximaciones o alejamientos evolutivos con respecto al Buxus latino, tenemos el vocablo ezpel, que aparecerá en los Ezpeleta (conjunto de bojes o bojal) de Arexola (Aramaio), Musitu (Laminoria) y San Román de Campezo.

Aquí finaliza un recorrido limitado en el espacio y en el tiempo, conjugando nombres y paisaje, ligados a la presencia del hombre en una Naturaleza que a su evolución propia une la inducida por nuestra actividad, en muchos casos tentativa como la de este glosario.

\section{BIBLIOGRAFÍA}

Aizpuru, I.; Catalán, P. y Garín, F.; 1996. Guía de los árboles y arbustos de Euskal Herria. Publicaciones del Gobierno Vasco. Vitoria-Gasteiz.

GonZÁlez MíngueZ, C.; 1977. La etapa medieval, Historia de una ciudad. Vitoria I, El núcleo medieval. Bankoa, 23-44. Vitoria.

GonzÁlez SAlazAR, J.A.; 2005. Montaña Alavesa. Comunidades y pastores. Colección OHiTURA 11. Diputación Foral de Álava. Vitoria-Gasteiz.

López de Guereñu Galarraga, G.; 1989. Toponimia alavesa, seguido de Mortuorios o despoblados y Pueblos alaveses. Euskaltzaindia. Bilbao.

López de Guereñu Galarraga, G.; 1998 (1956). Voces alavesas. Euskaltzaindia. $2^{\mathrm{a}}$ edición. Bilbao.

MichelenA, L.; 1955 (1953). Apellidos Vascos. Biblioteca Vascongada de los Amigos del País, $2^{\mathrm{a}}$ edición. San Sebastián.

MitXelena K., SARAsola, I. et al.; 1987-2005. Diccionario General Vasco/ Orotariko Euskal Hiztegia. Euskaltzaindia. Bilbao.

Real ACAdemia Española; 1992. Diccionario de la Lengua Española. RAE, 21 ${ }^{\mathrm{a}}$ edición. Madrid.

RUIZ DE LA TORRE, J.; 1971. Árboles y arbustos de la España peninsular. IFIE-ETSIM. Madrid.

Ruiz Urrestarazu, M.M.a; 1973. Especies Forestales Arbóreas en la Toponimia Vasca. ETSIM (tesis doctoral, sin publicar). Madrid.

Ruiz Urrestarazu, M.M.; 2008. Acer eta Quercus espezieen euskal izenak. Revista EUSKERA Agerkaria 53 liburukia(2.aldia): 397-409.

Servicio de Montes de LA DFA; 1980. Actualización del Catálogo de Montes de Utilidad Pública de la Provincia de Álava. Diputación Foral de Álava. Vitoria-Gasteiz. 